\title{
HORSESHOE KIDNEY WITH ACCESSORY RENAL ARTERY AND EXTRARENAL CALYCEAL SYSTEM - A CASE REPORT
}

Udayasree. L, Ganesh T Waghmode.

1. Assistant Professor, Department of Anatomy, NRIIMS, Sangivalasa, Visakhapatnam.

2. Associate Professor, Department of Anatomy, NRIIMS, Sangivalasa, Visakhapatnam.

\section{CORRESPONDING AUTHOR:}

Dr. Udayasree. L,

D.No.16-3-5/8,

A2 - Dayal Apartments,

Official Colony - $1^{\text {st }}$ Line,

Maharanipeta, Vishakhapatnam - 530002.

E-mail: thesensitiveramesh@gmail.com

\begin{abstract}
The congenital anomalies of kidney are important as they may cause renal failure in middle age group. The horseshoe kidney is the most common congenital fusion anomaly in which both kidneys were fused at their lower poles by an isthmus in front of the inferior vena cava and the abdominal aorta. We present a case report of horseshoe kidney with long hilum opened anteriorly and extrarenal calyces in the left kidney along with an accessory renal artery arising from the aorta, supplied to lower pole of the left kidney and there was a separate renal vein opening into the inferior vena cava. The knowledge of horseshoe kidney with accessory renal vessels and extrarenal calyceal system is helpful for surgeons or urologists during operations.
\end{abstract}

KEY WORDS: horseshoe kidney, accessory renal artery, extrarenal calyces and renal hilum.

MeSH TERMS: $\quad$ Kidney calices - A05.810.453.537.503

$$
\begin{array}{ll}
\text { Renal artery } & \text { - A07.231.114.745 } \\
\text { Renal vein } & \text { - A07.231.908.752 }
\end{array}
$$

INTRODUCTION: The occurrence of horseshoe kidney is about $0.25 \%$ in general population, (1) and are seen in approximately 1 out of 300 pyelographies. $(2,3)$ Horseshoe kidney is found in 1 out of 1000 necropsies and more common in men. The horseshoe kidney was usually asymptomatic because there was normal development of calyceal system. The horseshoe kidneys are liable to urinary flow obstruction at pelviureteric junction, infection and stone formation. (4) About 7\% of persons with Turner's syndrome have horseshoe kidney. However, the horseshoe kidney with extrarenal calyces and an accessory renal artery on the left side is a rare association and this has prompted the authors to report the case.

CASE REPORT: The present report was about a horseshoe kidney found in approximately 55 years old male cadaver during routine dissection practice for undergraduate students. The horseshoe kidney was located in front of the aorta and the inferior vena cava at the junction between L3 \& L4 vertebrae. The lower pole of both kidneys was fused by the isthmus and was below the origin of inferior mesenteric artery. The inferior mesenteric vessels passed in front of the isthmus (fig no: 1). 
The arterial supply of right kidney was provided by the right renal artery that originated from the lateral surface of the abdominal aorta. It was divided into anterior and posterior branches and then into upper and lower branches. The left kidney was supplied by left renal artery, which was a lateral branch of the abdominal aorta and divided into anterior, posterior and then into upper \& lower branches. The lower pole of the left kidney was supplied separately by an accessory renal artery, which was a branch of the aorta. No separate blood supply to the isthmus.

Two renal veins, right \& left, were draining the horseshoe kidney into the inferior vena cava. The lower pole of left kidney was drained by a separate vein into the inferior vena cava.

The hilum of right kidney was short and opened medially. The hilum of the left kidney was long \& opened anteriorly. Both ureters passed in front of the isthmus. The right pelvis was directed medially. Small minor calyces joined to form two major calyces which again joined to form pelvis of the ureter. All these were present outside the left kidney. Both ureters passed in front of the isthmus (fig no: 2).

\begin{tabular}{|l|c|c|c|}
\hline \multicolumn{4}{|c|}{ Dimensions of the Horseshoe kidney and hilar structures } \\
\hline & LEFT (mm) & RIGHT (mm) & ISTHMUS (mm) \\
\hline Length & 123 & 115 & 30 \\
\hline Width & 55 & 54 & 12 \\
\hline Thickness & 33 & 50 & 3 \\
\hline Length of Hilum & 102 & 46 & \\
\hline Diameters: & & & \\
\hline Renal Artery & 4 & 5 & \\
\hline Renal Vein & 6 & 10 & \\
\hline Accessory Renal Artery & 3 & & \\
\hline Accessory Renal Vein & 2 & & \\
\hline Ureter & 4 & 220 & \\
\hline Length of Ureter & 195 & & \\
\hline
\end{tabular}

DISCUSSION: EMBRYOGENESIS: Notochord is not necessary for nephrogenesis but is required for correct positioning of the metanephric kidney, while the axial sonic hedgehog gene signal is critical for kidney positioning along the mediolateral axis. Any disruption of this gene or notochord will result in kidney fusions. (5) In our report, the specimen presents a horseshoe kidney with lower poles fused by the fibrous isthmus. The position of the horseshoe kidney can be anywhere from the normal lumbar location to the pelvis. In our report, it is present below the origin of inferior mesenteric artery. The measurements of the kidneys considered individually had small variations, but were within expected limits.

In the present case, a renal artery for each kidney was found that originated as lateral branches of the abdominal aorta and an accessory renal artery to the lower pole of the left kidney, arising from the aorta distal to the origin of inferior mesenteric artery. Graves ${ }^{6}$ described $^{2}$ 'extra' or 'aberrant and anomalous' arteries were in fact normal segmental vessels whose origin was more proximal than usual and these extra or aberrant source of supply to that part provided by the main renal stem. 


\section{CASE REPORT}

In the present report, hilum of the left kidney opened anteriorly with extrarenal calyceal system. Similar case was presented by Malament et $\mathrm{al}^{7}$. According to Malament et $\mathrm{al}^{7}$, lag in the growth of the nephrogenic mass could delay its attachment to the collecting system and malrotation permitting extrarenal development of the first or second order of the collecting system.

ACKNOWLEDGEMENT: We extend our thanks to Mr. R.V.S. Bhaskar, Office Superintend, Department of Anatomy, NRIIMS, Sangivalasa, Visakhapatnam, A.P [India].

\section{REFERENCES:}

1. Allen A.C. the kidney: Medical and Surgical Diseases, Grune \& Stratton, Inc., New York: 1951; p.94.

2. Dees, J.E: Clinical importance of congenital anomalies of upper urinary tract. Journal of Urology. 1941; 46: pp.659-666.

3. Lowsley O.S. Surgery of horseshoe kidney. Journal of Urology. 1952; 67, pp.565-578.

4. Christopher G Fowler. The kidneys and ureters. In: Norman S. Williams, C. J. K. Bulstrode, P. Ronan O'Connell editors: Bailey \& Love's Short practice of surgery, $26^{\text {th }}$ ed. London, CRC Press, Taylor \& Francis group, 2013; Chapter75, pp.1282 \& 1283.

5. Ellen Shapiro, Stuart B. Bauer, Jeanne S. Chow. Anomalies of the upper urinary tract. In: Alan J. Wein editor. Campbell-Walsh urology, 10 ${ }^{\text {th }}$ ed, vol4: Philadelphia. Elsevier Saunders. 2012; chapter 117, p.3145.

6. Graves F T. The aberrant renal artery. J Anat. 1956; 90: pp.553-558.

7. Malament M, Schwartz B, Nagamatsu G R. Extrarenal calyces: their relationship of renal disease. American Journal of Roentgenology. 1961; 86: pp.823-829. 


\section{CASE REPORT}

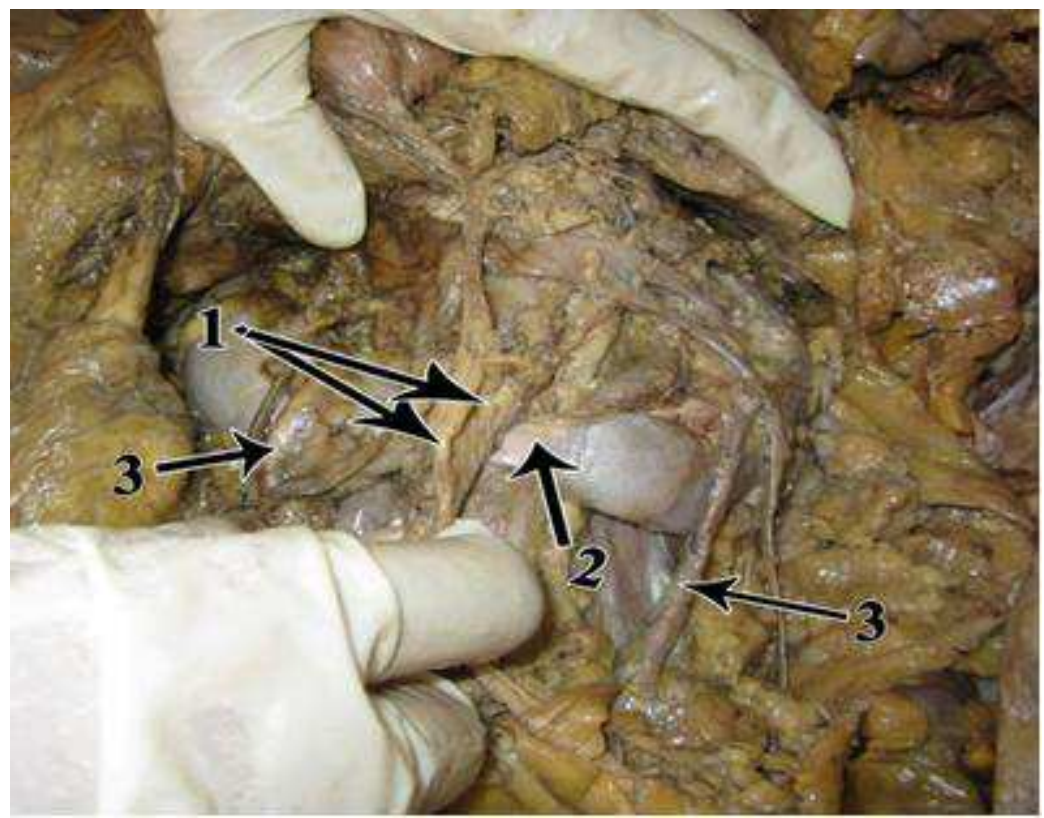

FIG 1: Showing horseshoe kidney;

1. Inferior mesenteric vessels, 2. Isthmus, 3. Ureter.

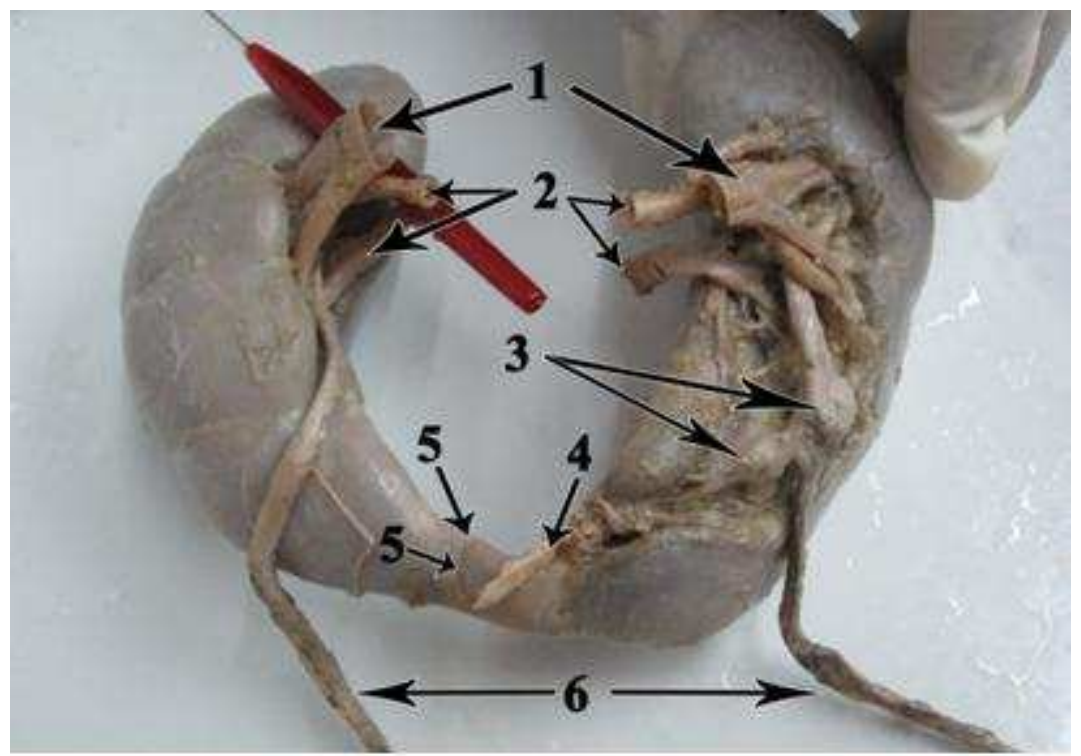

FIG 2: Showing horseshoe kidney with renal vessels, extrarenal calyceal system;

1. Renal vein, 2. Renal artery, 3. Extrarenal calices, 4. Accessory renal artery, 5. Isthmus, 6. Ureter. 